\title{
EFFICACY OF PERCUTANEOUS NEPHROLITHOTOMY IN THE TREATMENT OF RENAL CALCULI OF 10 TO 20 MM SIZE: A COMPARISON WITH EXTRACORPOREAL SHOCK WAVE LITHOTRIPSY
}

\author{
MUHAMMAD MAHMUD ALAM ${ }^{1}$, MOHAMMAD REZAUL KARIM ${ }^{2}$, MOHAMMAD OHIDUZZAMAN KHAN ${ }^{3}$, \\ MOHAMMAD MUKHLESUR RAHMAN ${ }^{4}$, MAHFUJA ASMA ${ }^{5}$, AKM ANWARUL ISLAM ${ }^{6}$
}

\begin{abstract}
Background: Stones in the urinary tract is a common medical problem in the general population. At present, the great expansion in minimally invasive techniques has led to the decrease in open surgery. Extracorporeal shock wave lithotripsy (ESWL) has been introduced as an alternative approach which disintegrates stones in the kidney and upper urinary tract through the use of shock waves. Nevertheless, as there are limitations with the success rate in ESWL, other minimally invasive modalities for kidney stones such as percutaneous nephrolithotomy (PCNL) is also widely applied. There is a trend of using ESWL for treatment of renal stones smaller than $1 \mathrm{~cm}$ and PCNL in those with stones greater than $2 \mathrm{~cm}$. Nevertheless, no consensus regarding treatment of renal stones between 1 to $2 \mathrm{~cm}$ stones. The objective of this prospective study was to compare the results of ESWL and PCNL for treatment of 1 to $2 \mathrm{~cm}$ renal stones.
\end{abstract}

Method: This is a quasi experimental study. This study was conducted to compare the efficacy and safety of percutaneous nephrolithotomy (PCNL) and extracorporeal shock wave lithotripsy (ESWL) in treating 10 to $20 \mathrm{~mm}$ sized renal stone among the Bangladeshi population. This prospective study conducted between the periods of September, 2011 to August, 2012 in the department of urology, Bangabandhu Sheikh Mujib medical university (BSMMU) Hospital. All the patients attending the urology outpatient clinic with 10 to $20 \mathrm{~mm}$ renal calculi were the study population. A total of 70 subjects were enrolled for this study and they were equally divided into two groups so that each group had 35 subjects. The one group received PCNL whereas the other group received ESWL. Statistical analyses of the results were obtained by using window based computer software devised with Statistical Packages for Social Sciences (SPSS-15).

Results: There is no statistically significant difference in regarding age, sex, stone side(It. or rt.), the distribution of stone (upper, middle and lower calyx) and size between the groups ( $p>0.05)$. At 3 month follow up among the patients in ESWL group stone cleared and not cleared were $25(71.4 \%)$ and 10(28.6\%) respectively and at 3 month follow up among the patients in PCNL group stone cleared and not cleared were 33(94.3\%) and $2(5.7 \%)$ respectively. There is statistically significant difference in stone clearance rate at 3 month follow up between the groups $(p<0.05)$. All patients in ESWL group developed post procedure haematuria 35(100.0\%). Other post procedure complications among the ESWL group pain, fever and steinstrasse were 12(34.3\%), 07(20.0\%) and 03(08.6\%) respectively. Common post procedure complications among the patients of PCNL group pain, haematuria and fever were 11(31.4\%), 33(94.3\%) and 13(37.1\%) respectively.

1. Resident Surgeon, Mugda Medical College \& Hospita, Dhaka

2. Assistant Professor, Dept. of Urology, Patuakhali Medical College, Patuakhali.

3. Assistant Professor, Dept. of Urology, Faridpur Medical College, Faridpur.

4. Assistant Professor, Dept. of Urology, Syed Nazrul Islam Medical College, Kishoregonj.

5. Consultant, Obstetrics \& Gynaecology,Mugda Medical College \& Hospital, Dhaka

6. Professor, Dept. of Urology, Bangabandhu Sheikh Mujib Medical University, Dhaka

Correspondence : Dr. Muhammad Mahmud Alam, Resident Surgeon, Mugda Medical College \& Hospital, Dhaka, Mobile -01819231408, E-mail: tariquro@gmail.com

Received: 9 August 2017

Accepted: 05 March 2018 
Other post procedure complications in PCNL group were vomiting (8.6\%), urinary leakage (5.7\%), wound infection (11.4\%) and urinary cutaneous fistula (5.7\%). There was no statistically significant difference post procedure pain, haematuria and fever between the groups ( $p>0.05$ ), but statistically significant difference observed in steinstrasse and wound infection between the groups $(p<0.05)$. Mean $\pm S D$ of hospital stay among the patients of ESWL group and PCNL group was $1.37 \pm 0.65$ and $4.34 \pm 1.43$ days respectively. There is statistically significant difference in hospital stay between the groups $(p<0.05)$. Conclusion: Though some specific complications which can be treated conservatively are more in PCNL group it may be concluded that the treatment with PCNL is better option than ESWL among the patients having renal calculi 10 to $20 \mathrm{~mm}$.

Bangladesh J. Urol. 2018; 21(2): 98-104

\section{Introduction}

Urinary stone disease is a systemic metabolic and recurrent disease. It is the third most common disease of the urinary tract, exceeded only by urinary tract infections and pathologic conditions of prostate. ${ }^{1}$ Urolithiasis affects $4 \%$ to $15 \%$ of the world population and the incidence of this is increasing, especially in Europe. ${ }^{2}$ Though there is no exact data about its prevalence in Bangladesh but the problem is quite common.

Management of urolithiasis ranges from conservative watchful waiting to traditional open surgical procedure. In between these two, there exist a spectrum of procedures, which includes the recently developed noninvasive to minimally invasive procedures like extracorporeal shock wave lithotripsy (ESWL), percutaneous nephrolithotomy (PCNL), URS, and Laparoscopic removal. But one option can supplement other for total stone clearance. ${ }^{3}$

PCNL is a procedure of stone fragmentation and retrieval. The development of instruments designed for percutaneous nephrolithotomy permitted percutaneous technique to evolve a point where any stone could be removed from urinary tract with reasonable economy and morbidity.

ESWL has revolutionized the treatment of urinary stones with the concept to fragment stones only and leaving the fragments to pass naturally. The noninvasive nature, requirement of minimal or no anaesthesia and high level of patience acceptance, have made ESWL a preferred treatment for majority of symptomatic renal calculi requiring intervention.

Stone related factors (size, number, location and composition), renal anatomy and patient's clinical factors should all be considered in conjunction with various surgical modalities and the availability of equipment before the preferred surgical approach is selected. Stone size is perhaps the single most important factor in determining the appropriate treatment modality for a patient with renal calculi. Many studies have been done in different parts of the world to compare the results of PCNL and ESWL in the management of renal stone of different size. In the light of recent development of various modalities of treatment of renal stones this study has been designed to compare the results of treatment of renal calculi by extracorporeal shock wave lithotripsy and percutaneous nephrolithotomy for stone clearance of 10 to $20 \mathrm{~mm}$ sized renal calculi among the Bangladeshi population.

Very recently, dramatic development has been made in different types of health services in Bangladesh. Several health care institutions for the management of renal stone diseases have already been established in Dhaka and other parts of the country both in private and public sectors. Bangabandhu Sheikh Mujib medical university (BSMMU) hospital is a tertiary level hospital in Bangladesh. Sophisticated technology and multidimensional services have been added a new dimension in this hospital for health care services especially in the department of urology. So, to do this kind of study, department of urology of BSMMU Hospital is an ideal place.

\section{Materials \& Methods:}

It was a Quasi experimental study conducted in the department of urology, BSMMU, Dhaka. The present study conducted between the periods of September 2011 and August 2012. Patients having renal calculi size 10 to $20 \mathrm{~mm}$ attending the outpatient department of urology, BSMMU hospital were the study population. Total 70 patients were divided into two equal groups. In PCNL group 35 patients with renal stone treated with percutaneous nephrolithotomy and in ESWL group 35 patients with renal stone treated with extracorporeal 
shock wave lithotripsy. All patients received bowel preparation and oral antibiotic prophylaxis the day before the procedure. The one group received PCNL whereas the other group received ESWL. ESWL monotherapy with Siemens Lithoscope ( $3^{\text {rd }}$ generation) lithotripter was used to treat 35 renal calculi selected on preselected criteria. All stones will be $10-20 \mathrm{~mm}$ in size. Patients were instructed to take a mild laxative for one night with carbon tablets to help reduce intestinal gases and facilitate stone localization. All the patients were in nothing per oral from morning and were given intravenous fluid with diclofenac sodium suppository half an hour prior to the procedure. On demand, some were given I/V analgesia and sedation. They were placed in supine on the ESWL table. Stone was focused with the help of fluoroscopy and stones were fragmented. Some worried and restless patients may need sedative.

The patients were discharged on $3^{\text {rd }}$ postoperative day with an advice to come after 2-4 weeks depending on necessity of a $2^{\text {nd }}$ procedure or for removal of stent in situ. Patients were then observed up to 90 days for at least three follow up session. Those patients who suffered from any post procedure complications were evaluated properly and managed accordingly. Statistical analyses of the results were obtained by using window based computer software devised with Statistical Packages for Social Sciences (SPSS-15) (SPSS Inc, Chicago, IL, USA). The results were presented in tables, figures and diagrams. During analysis frequency distribution for all the variables was worked out and produced in tabular form. $\div^{2}$ tests were used to compare proportions. A two-sided $p$ value 0.05 was considered significant at $95 \%$ level.

Table-I

Demographic characteristics of the patients by groups

\begin{tabular}{lll}
\hline Characteristics & \multicolumn{3}{c}{ Group } \\
\cline { 2 - 3 } & ESWL & PCNL \\
\hline
\end{tabular}

Age in years

\begin{tabular}{lcc}
$<=20$ & $2(05.7)$ & $0(0.0)$ \\
$21-30$ & $8(22.9)$ & $01(02.9)$ \\
$41-50$ & $7(20.0)$ & $14(40.0)$ \\
$51-60$ & $6(17.1)$ & $10(28.6)$ \\
$>60$ & $3(08.6)$ & $02(05.7)$ \\
Mean \pm SD & $41.05 \pm 14.35$ & $47.37 \pm 9.26$ \\
Sex & & \\
Male & $24(68.6 \%)$ & $25(71.4 \%)$ \\
Female & $11(31.4 \%)$ & $10(28.6 \%)$ \\
\hline
\end{tabular}

Table-II

Distribution of stone clearance at 3 month follow-up by groups

\begin{tabular}{lccc}
\hline Follow up at & \multicolumn{2}{c}{ Group } & $\mathrm{p}$ \\
\cline { 2 - 3 } 3 months & ESWL & PCNL & value \\
\hline Stone cleared & $25(71.4 \%)$ & $33(94.3 \%)$ & 0.026 \\
Residual stone & $10(28.6 \%)$ & $02(05.7 \%)$ & \\
\hline Total & $35(100.0 \%)$ & $35(100.0 \%)$ & \\
\hline
\end{tabular}

Table-III

Distribution of upper, middle and lower calix stone clearance at 3 month follow-up

\begin{tabular}{|c|c|c|c|}
\hline \multirow[t]{2}{*}{ Stone site by IVU } & \multicolumn{2}{|c|}{ Group } & \multirow{2}{*}{$\begin{array}{c}\mathrm{p} \\
\text { value }^{\#}\end{array}$} \\
\hline & ESWL & $\mathrm{PCNL}$ & \\
\hline Stone & $16(84.2 \%)$ & $18(100.0 \%)$ & 0.2297 \\
\hline $\begin{array}{l}\text { Stone at upper calix } \\
\text { Stone not cleared } \\
\text { Stone at middle calix }\end{array}$ & $03(15.8 \%)$ & $0(0.0)$ & \\
\hline Stone cleared & $08(80.0 \%)$ & 10(90.9\%) & 0.929 \\
\hline $\begin{array}{l}\text { Stone not cleared } \\
\text { Stone at lower calix }\end{array}$ & $02(20.0 \%)$ & 01(09.1\%) & \\
\hline Stone cleared & $01(16.7 \%)$ & 05(83.3\%) & 0.083 \\
\hline Stone not cleared & $05(83.3 \%)$ & $01(16.7 \%)$ & \\
\hline
\end{tabular}

Table-IV

Distribution of use of analgesic at post procedure by groups

\begin{tabular}{lccc}
\hline Analgesic & \multicolumn{2}{c}{ Group } & $\mathrm{p}$ \\
\cline { 2 - 3 } & $\mathrm{ESWL}$ & $\mathrm{PCNL}$ & value $^{\#}$ \\
\hline Analgesic (single) & $30(85.7 \%)$ & $03(08.6 \%)$ & 0.001 \\
Analgesic (multiple) & $05(14.3 \%)$ & $32(91.4 \%)$ & 0.001 \\
\hline
\end{tabular}

Table-V

Distribution of complications at post procedure by groups

\begin{tabular}{lccc}
\hline Complications & \multicolumn{2}{c}{ Group } & $\mathrm{p}$ \\
\cline { 2 - 3 } & ESWL & PCNL & value \\
\hline Pain & $12(34.3 \%)$ & $11(31.4 \%)$ & 0.799 \\
Haemturia & $35(100.0 \%)$ & $33(94.3 \%)$ & 0.151 \\
Fever & $07(20.0 \%)$ & $13(37.1 \%)$ & 0.112 \\
Vomiting & $0(0.0 \%)$ & $03(08.6 \%)$ & 0.077 \\
Steinstrasse & $03(08.6 \%)$ & $0(0.0 \%)$ & 0.010 \\
Urinary leakage & $0(0.0 \%)$ & $02(05.7 \%)$ & 0.151 \\
Wound infection & $0(0.0 \%)$ & $04(11.4 \%)$ & 0.039 \\
Urinary cutaneous fistula0(0.0\%) & $02(05.7 \%)$ & 0.151 \\
\hline
\end{tabular}


Table-VI

Mean $\pm S D$ of hospital stay by groups

\begin{tabular}{lccc}
\hline Hospital stay & \multicolumn{2}{c}{ Group } & p value $^{*}$ \\
\cline { 2 - 3 } & ESWL & PCNL & \\
\hline Hospital stay (Days) & $1.37 \pm 0.65$ & $4.34 \pm 1.43$ & 0.001 \\
\hline
\end{tabular}

\section{Discussion}

The lifetime prevalence of kidney stone disease is estimated at $1 \%$ to $15 \%$, with the probability of having a stone varying according to age, gender, race, and geographic location. In the United States, the prevalence of stone disease has been estimated at $10 \%$ to $15 \%$.Though there is no exact data about its prevalence in Bangladesh but the problem is quite common.

PCNL is a procedure of stone fragmentation and retrieval. The development of instruments designed for percutaneous nephrolithotomy permitted percutaneous technique to evolve a point where any stone could be removed from urinary tract with reasonable economy and morbidity. ${ }^{4}$ ESWL has revolutionized the treatment of urinary stones with the concept to fragment stones only and leaving the fragments to pass naturally. The noninvasive nature, requirement of minimal or no anaesthesia have made ESWL a preferred treatment for majority of symptomatic renal calculi requiring intervention.

The present hospital based prospective study included 70 patients having renal calculi sized 10 to $20 \mathrm{~mm}$. They were divided in to two equal groups. In PCNL Group 35 patients were treated with percutaneous nephrolithotomy and in ESWL Group 35 patients were treated with extracorporeal shock wave lithotripsy. The study was conducted to compare the efficacy and safety of percutaneous nephrolithotomy (PCNL) and extracorporeal shock wave lithotripsy (ESWL) in treating 10 to $20 \mathrm{~mm}$ sized renal stone among the Bangladeshi population.

In the present study the mean \pm SD of age ESWL and PCNL group was $41.05 \pm 14.35$ and $47.37 \pm 9.26$ years respectively. The age range in ESWL group was 17 to 68 years and in PCNL group 18 to 73 years. Highest number in ESWL group were in the age range of 31 to 40 years $(25.7 \%)$ followed by 21 to 30 years $(22.9 \%)$ and 41 to 50 years (20\%). Highest number in PCNL group were in the age range of 41 to 50 years $(40.0 \%)$ followed by 51 to 60 years (28.6\%) and 31 to 40 years $(22.9 \%)$. Kupeli et al. ${ }^{5}$ in their study showed that the mean age of the patients with renal calculi was 39.11 years with a ranged from 17 to 70 years. Turna et al. ${ }^{6}$ in a study retrospectively analyzed the data of 193 patients (193 PCNL procedures) where mean patient age was $45.7 \pm 14.4$ years with a range of range 15 to 74 years. The age distribution of this study was more or less same with the above two studies.

Out of 35 patients in ESWL group 24 (68.6\%) were male and $11(31.4 \%)$ were female. Among the 35 patients in PCNL group 25 (71.4\%) were male and 10 $(28.6 \%)$ were female. There is no statistically significant difference in sex between the groups $(p>0.05)$. The cause of more male patients in this study is due to the fact that the stone disease typically affects adult men more commonly than adult women. By a variety of indicators including inpatient admissions, outpatient office visits, and emergency department visits, men are affected two to three times more often than women. ${ }^{7,8,9}$

Among the 35 patients in ESWL group, 16(45.7\%) had stone on right side and $19(54.3 \%)$ had stone on the left side. Among the 35 patients in PCNL group, $17(48.6 \%)$ had stone in right side and $18(52.4 \%)$ had stone in the left side.

Mean \pm SD of stone size among the ESWL group was $17.6 \pm 2.8 \mathrm{~mm}$ and $16.1 \pm 3.4 \mathrm{~mm}$ in the right side and left side respectively. Mean \pm SD of stone size among the PCNL group was $18.2 \pm 1.8 \mathrm{~mm}$ and $17.1 \pm 2.3 \mathrm{~mm}$ in the right side and left side respectively. There is no statistically significant difference in stone side and size between the groups $(p>0.05)$.

Among the 35 patients in ESWL group, stones located in upper calix, middle calix and lower calix were $19(54.3 \%), 10(28.6 \%)$ and $6(17.1 \%)$ respectively. Among the 35 patients in PCNL group, stones located in upper calix, middle calix and lower calix were present in $18(51.5 \%), 11(31.4 \%)$ and $6(17.1 \%)$ respectively. There is no statistically significant difference in stone location between the groups ( $p>0.05)$.

At 3 month follow up among the patients in ESWL group stone cleared and not cleared were $25(71.4 \%)$ and $10(28.6 \%)$ respectively and at 3 month follow up among the patients in PCNL group stone cleared and not cleared were $33(94.3 \%)$ and $2(5.7 \%)$ respectively. There is statistically significant difference in stone clearance at 3 month follow up between the groups $(p<0.05)$. Deem et al. ${ }^{10}$ compared the outcomes of PCNL with ESWL and showed that PCNL established a stone-free status of $95 \%$ and $85 \%$ at 1 week and 3 
months, respectively, whereas ESWL established a stone-free status of $17 \%$ and $33 \%$ at 1 week and 3 months, respectively. Albala et al. ${ }^{11}$ showed that the 3 month postoperative overall stone-free rates were $95 \%$ for percutaneous removal versus $37 \%$ with lithotripsy $(p<0.001)$.

Shameem et al. ${ }^{12}$ compared the results of percutaneous nephrolithotomy and shock wave lithotripsy for the treatment of 1 to $2 \mathrm{~cm}$ renal stones in children and in their study stone-free rate after a single session of percutaneous nephrolithotomy was $86.6 \%$ (71 units), and the remaining 11 kidneys with residual stones were successfully treated with repeat percutaneous nephrolithotomy in seven patients and shock wave lithotripsy in four patients. Therefore, a total of 78 units (95\%) were stone-free after percutaneous nephrolithotomy monotherapy, and the overall stonefree rate at 3 months was $100 \%$. A total of 79 units $(84.9 \%)$ were stone-free after shock wave lithotripsy monotherapy, whereas 7 (7.5\%) with no gross response to treatment were treated with percutaneous nephrolithotomy and 7 with insignificant stones less than $4 \mathrm{~mm}$ were followed. The overall re-treatment rate after shock wave lithotripsy was $55 \%$. Of the patients undergoing shock wave lithotripsy $1(1.1 \%)$ developed steinstrasse and was successfully treated with ureteroscopy. This result more or less consistent with the present study.

In the present study at the end of 3 month follow up out of 19 stones in upper calix in ESWL group, 16(84.2\%) were cleared and 03(15.8\%) were not cleared. All stones in upper calix in PCNL group were cleared. Out of 10 stones in middle calix in ESWL group, 8 (80.0\%) were cleared and $2(20.0 \%)$ were not cleared. All stones in middle calix, except one $(9.1 \%)$ in PCNL group were cleared. Out of 6 stones in lower calix in ESWL group, only one $(16.7 \%)$ was cleared and $5(83.3 \%)$ were not cleared. All stones in lower calix, except one $(9.1 \%)$ in $\mathrm{PCNL}$ group were cleared. It is to be noted that clearance of stone in PCNL group occurred at the time of procedure. There is no statistically significant difference in stone clearance in upper, middle and lower calix between the groups $(p>0.05)$.

In this study although there is a visual difference in lower caliceal stone clearance but that is not statistically significant. This may be due to the small sample size in lower calix group. In a study by Havel et al. ${ }^{13} \mathrm{PCNL}$ achieves statistically significant results than ESWL for single middle-size stone of the lower pole but with higher morbidity. In a study Sumino et al. ${ }^{14}$ analyzed several anatomical factors as predictors of lower pole stone clearance by ESWL and showed that the overall stone clearance rate was $54 \%$ (34 of 63 patients). Kupeli et al. ${ }^{5}$ reported the overall stone-free rate at 3 months by ESWL was $53.33 \%$; whereas it was $61.79,48.27$, and $27.27 \%$ according to the stone size, d"10, $11-20$ and e"21 mm, respectively. The results of ESWL and PCNL for the treatment of lower pole nephrolithiasis were examined by Lingeman et al. ${ }^{15}$ and reported stonefree rate in PCNL $90 \%$ and in ESWL 59\%. Stone-free rates with $\mathrm{PCNL}$ were independent of stone burden, whereas stone-free rates with ESWL were inversely correlated to the stone burden. Cass ${ }^{16}$ reviewed their results with 968 single lower pole stones treated by ESWL and reviewed publications comparing ESWL and PCNL for lower pole nephrolithiasis and they found the stone-free rate was $71.2 \%$ in ESWL.

Among the patients in ESWL group, 10 (28.6\%) were required adjuvant procedure for stone clearance and in PCNL group only 2 (5.7\%) were required adjuvant procedure. There is statistically significant difference in requirement of adjuvant procedure between the groups $(p<0.05)$. Deem et al. ${ }^{11}$ compared the outcomes of PCNL and ESWL and showed that retreatment in ESWL was required in $67 \%$ of cases, with $0 \%$ retreatment in PCNL. Netto et al. ${ }^{17}$ in their study showed that the complete removal of all stone fragments was achieved in $93.6 \%$ of the patients treated with PCNL without retreatment and in the ESWL group with a $41.6 \%$ retreatment rate. The finding in this study is very much consistent with the other studies mentioned.

Among the 35 patients in ESWL group 30 (85.7\%) were treated with single analgesic and only $5(14.3 \%)$ required multiple analgesic. Among the 35 patients in PCNL group $32(91.4 \%)$ were treated with multiple analgesic and only $3(8.6 \%)$ required single analgesic. There is statistically significant higher dose and number in analgesic requirement in the PCNL group $(p<0.05)$.

All patients in ESWL group developed post procedure haematuria $35(100 \%)$. Post procedure haematuria developed in $33(94.3 \%)$ cases of PCNL group. Other post procedure complications among the of ESWL group were pain, fever in $12(34.3 \%), 07(20.0 \%)$ and in PCNL group 11(31.4\%), 13(37.1\%) respectively. There is no statistically significant difference regarding post procedure pain, haematuria and fever between the groups $(p>0.05)$. Other post procedure complications 
in PCNL group were urinary leakage (5.7\%), wound infection (11.4\%) and urinary cutaneous fistula $(5.7 \%)$. 3 patients( $8.6 \%)$ in ESWL group developed steinstrasse but none in the PCNL group. Statistically significant difference observed in steinstrasse (ESWL) and wound infection (PCNL) between the groups $(p<0.05)$.

Netto et al. ${ }^{17}$ in their study showed that the patients who underwent a percutaneous operation $13 \%$ had complications compared to $4.1 \%$ in the ESWL group. Kupeli et al. ${ }^{5}$ studied to determine the effectiveness of extracorporeal shock wave lithotripsy (ESWL) therapy and reported that complications were rare, including 2 pyelonephritis, 2 subcapsular hematoma formation, 24 renal colics and 8 stone streets, which were managed by ureteral stenting or additional ESWL and resulted in complete stone clearance.

Lee et al. ${ }^{18}$ studied the complications of PCNL. In their study they found complications in $4 \%$ cases. The most common complications in their study were fever $(23 \%)$ and bleeding necessitating transfusion (12\%). Extravasation was seen in $7 \%$ of patients and transient ureteral obstruction in $6 \%$. Other complications included pneumothorax or hydrothorax, pneumonia/atelectasis, paralytic ileus, nephrostomy-tube dislodgment or urine drainage from the flank lasting more than 1 week, significant infection, urinoma formation, renal pelvic laceration, ureteral avulsion, ureteropelvic or ureteral stricture, bowel injury, or escape of stone fragments into the retroperitoneum. Michel et al. ${ }^{19}$ reviewed a step-by-step approach to percutaneous nephrolithotomy (PCNL) and its complications and management. Based on institutional and personal experience with $>1000$ patients treated by $\mathrm{PCNL}$, they reviewed the literature (Pubmed search) focusing on technique, type, and incidence of complications of the procedure. Complications during or after PCNL may be present with an overall complication rate of up to $83 \%$, including extravasation $(7.2 \%)$, transfusion (11.2$17.5 \%)$, and fever $(21.0-32.1 \%)$, whereas major complications, such as septicaemia $(0.3-4.7 \%)$ and colonic $(0.2-0.8 \%)$ or pleural injury (0.0-3.1\%) are rare.

ESWL is an effective noninvasive procedure without the need for routine anesthesia and hospitalization with prompt return of the patient to a normal life. ${ }^{17}$ In the present study the mean \pm SD of hospital stay among the patients of ESWL group and PCNL group was $1.37 \pm 0.65$ and $4.34 \pm 1.43$ days respectively. There is statistically significant difference in hospital stay between the groups $(p<0.05)$. Netto et al. ${ }^{17}$ in their study showed that the ESWL group had a shorter hospitalization and an earlier return to normal physical activities. Cass ${ }^{16}$ in his study reported that the hospital stay was less than 24 hours in $99.3 \%$ of patients treated by ESWL and among the patients treated by PCNL was 3.1 to 6.1 days. These results correlate with the present study.

In considering the overall stone clearance rate PCNL is the better option for the treatment of renal calculi though in terms of complications and hospital stay ESWL is the better option.

\section{Conclusion}

In the present study PCNL shows better result than ESWL in stone clearance at 3 month follow up which is statistically significant. Though some specific complications which can be treated conservatively are more in PCNL group it may be concluded that the treatment with PCNL is better option than ESWL among the patients having renal calculi sized 10 to $20 \mathrm{~mm}$.

\section{References}

1. Stoller, ML and Bolton, DM 2000, 'Urinary Stone Disease', In Tangaho EA, Mcaninch JW (eds), Smith's General Urology. $15^{\text {th }}$. Ed. 2000, Lange medical books/ McGraw - Hill, Sanfrancisco, pp.291-320.

2. Bora Kupeli, Irkilata, L and Gourocak, S 2004, 'Does tamsulosin enhance lower ureteral stone clearence with or without shock wave lithotripsy?', Urology, vol.64, pp.1111-1115.

3. Martin, X, Tolley, D, Galluci, M and Alken, P 2001, 'The difficult stone case: Definition and management', European Urology, vol.40, pp.1-9.

4. Skenazy, J, Ercole B, Lee C, Best S, Fallon E and Monga, M 2005, 'Nephrolithiasis: "scope," shock or scalpel?', Journal of Endourology / Endourological Society, vol.19, no.1, pp.45-49.

5. Kupeli, B, Biri, H, Sinik, Z, Karaca, K, Tuncayengin, A, Karaoglan $U$ and Bozkirli, I 1998, 'Extracorporeal shock wave lithotripsy for lower caliceal calculi', Eur Urol, vol.34, no.3, pp.203-206.

6. Turna, B, Nazli, O, Demiryoguran $S$ and Mammadov, R 2007, 'Percutaneous nephrolithotomy: variables that influence hemorrhage', Urology, vol.69, no. 4, pp.603-607. 
7. Honey, J 2008, 'Treating lower pole renal stones: in defence of shock wave lithotripsy' Can Urol Assoc J, vol. 2, no.6, pp.625-627.

8. Sumino, $\mathrm{Y}$, Mimata $\mathrm{H}$, Tasaki $\mathrm{Y}$, Ohno $\mathrm{H}$ and Hoshino, T 2002, 'Predictors of lower pole renal stone clearance after extracorporeal shock wave lithotripsy' J Urol, vol.168, pp. 1344-1347.

9. Paterson, RF, Lifshitz, DA, Kuo, RL and Lingeman, JE 2002, 'Shock wave lithotripsy monotherapy for renal calculi', International Braz J Urol, vol. 28, no.4, pp. 291-301.

10. Deem, S, Defade, B, Modak, A, Emmett, M, Martinez, F and Davalos, J 2011, 'Percutaneous nephrolithotomy versus extracorporeal shock wave lithotripsy for moderate sized kidney stones', Urology, vol.78, no. 4, pp.739-743.

11. Albala, DM, Assimos, DG, Clayman, RV, Denstedt, JD and Grasso, M 2001, 'A prospective randomized trial of extracorporeal shock wave lithotripsy and percutaneous nephrostolithotomy for lower pole nephrolithiasis-initial results', J Urol, vol.166, no.6, pp.2072-2080.

12. Shameem, IA, Islam, $K$, Islam AKMA, Salam, MA and Wahab, MA 2001, 'Management of ureteral stones by in situ ESWL', Bangladesh Journal of Urology, vol.4, pp.14-15.

13. Havel, D, Saussine, C, Fath, C, Lang, H, Faure, $F$ and Jacqmin, D 1998, 'Single stones of the lower pole of the kidney-Comparative results of extracorporeal shock wave lithotripsy and percutaneous nephrolithotomy', European Urology, vol. 33, no. 4, pp.396-400.

14. Sumino, $\mathrm{Y}$, Mimata $\mathrm{H}$, Tasaki $\mathrm{Y}$, Ohno $\mathrm{H}$ and Hoshino, T 2002, 'Predictors of lower pole renal stone clearance after extracorporeal shock wave lithotripsy' J Urol, vol.168, pp. 1344-1347.

15. Lingeman, JE, Siegel, YI, Steele, B and Nyhuis, AW 1994, 'Management of lower pole nephrolithiasis: a critical analysis, Urol, vol.151, no. 3, pp.663-667.

16. Cass, AS 1996, 'Extracorporeal shockwave lithotripsy or percutaneous nephrolithotomy for lower pole nephrolithiasis?', Journal of Endourology, vol.10, no.1, pp.17-20.

17. Netto, NR, Claro, JF, Lemos, GC and Cortado, PL 1991, 'Renal calculi in lower pole calices: what is the best method of treatment?', The Journal of Urology, vol.146, no. 3, pp.721-723.

18. Lee, WJ, Smith, AD, Cubelli, V, Badlani, GH and Lewin, B 1987, 'Complications of percutaneous nephrolithotomy', AJR Am J Roentgenol, vol.148, no.1, pp.177-180.

19. Michel, MS, Trojan, L and Rassweiler, JJ 2007, 'Complications in percutaneous nephrolithotomy', European Urology, vol.51, no. 4, pp.899-906. 